\title{
METODOLOGIAS ATIVAS DE ENSINO: EVIDÊNCIAS DA APLICAÇÃO DO MÉTODO DE CASO NOS CURSOS DE CIÊNCIAS CONTÁBEIS E ADMINISTRAÇÃO
}

ACTIVE TEACHING METHODOLOGIES: EVIDENCE OF THE
APPLICATION OF THE CASE METHOD IN ACCOUNTING AND
BUSINESS ADMINISTRATION

0 artigo foi aprovado e apresentado na XVIII USP International Conference in Accounting, realizada de 25 a 27/7/2018, em São Paulo (SP). 0 presente trabalho fo desenvolvido com 0 apoio da Coordenação de Aperfeiçoamento de Pessoal de Nível Superior (Capes) - Código de Financiamento 001.

\section{RESUMO}

O presente estudo busca examinar os benefícios da utilização do Método do Caso, bem como suas limitações, tendo como base a Teoria da Difusão da Inovação. O estudo enquadra-se como qualitativo, sendo a coleta de dados realizada por meio de questionários, entrevistas, grupo focal e observação participante. A unidade de análise é composta por 46 estudantes que participaram desta intervenção pedagógica, distribuídos entre uma turma de Controladoria Empresarial de graduação em Ciências Contábeis e uma turma de Marketing do curso de Administração. Adicionalmente, visando complementar os achados da pesquisa, foram coletadas informações por meio de entrevistas com os docentes das disciplinas supracitadas. Após transcrição das entrevistas e grupos focais, foi realizada a codificação aberta para posterior análise de conteúdo por meio do software Atlas.ti. Os principais resultados evidenciaram que os estudantes apresentam uma boa aceitação do Método do Caso, ainda que, em um primeiro momento, exista resistência por parte de alguns alunos. No tocante às vantagens observadas por eles, foi relatado que o método possibilita visualizar os assuntos abordados em sala de aula de forma mais holística, além de facilitar a aproximação entre a teoria e a prática profissional. Em síntese, essas evidências corroboram a perspectiva dos educadores das disciplinas, uma vez que eles também percebem as vantagens do Método do Caso no processo de ensino-aprendizagem. Por fim, verifica-se, sob a Teoria da Difusão da Inovação, que o Método de Caso possui os aspectos suficientes para ser difundido, que são a vantagem relativa, compatibilidade, complexidade, "experimentabilidade" e "observabilidade".

Palavras chave: Método do Caso, Aprendizagem Baseada em Casos, Metodologias Ativas de Ensino.

\begin{abstract}
The present study examines the benefits of using the Case Method, as well as its limitations, based on the Innovation Diffusion Theory. The research is qualitative; evidence collection was performed through questionnaires, interviews, focus group, and participant observation. The unit of analysis consists of 46 students who participated in this pedagogical intervention, distributed between an undergraduate controllership class in accounting, and a marketing class in business administration. Additionally, to complement the research findings, information was collected through interviews with the teachers of the above disciplines. After transcribing the interviews and focus groups, open coding was performed for further content analysis using the Atlas.ti software. The main results show that the students had good acceptance of the Case Method, although at first there is resistance from some students. Regarding the advantages observed by them, it was reported that the method allows viewing the subjects approached in the classroom in a more holistic way, besides facilitating the approximation between theory and professional practice. In short, this evidence corroborates the educator's perspectives since they also perceive the advantages of the Case Method in the teaching-learning process. Finally, it is verified, under the Innovation Diffusion Theory, that the Case Method has the sufficient aspects for its diffusion, which are the relative advantage, compatibility, complexity, "experimentability" and "observability".
\end{abstract}

Keywords: Case Method, Case Based Learning, Active Teaching Methodologies.
José Mauro Madeiros Velôso Soares Doutorando em Ciências Contábeis pela Universidade do Vale do Rio dos Sinos. Mestre em Ciências Contábeis pela Universidade Federal do Rio Grande do Norte (2019). Especialista em IFRS e NBC pela Universidade do Estado do Rio Grande do Norte (2018). Docente do curso de Ciências Contábeis na Universidade Federal Rural do Semiárido. Endereço: Av. Dr. Nilo Peçanha, 1600 - Boa Vista, Porto Alegre - RS, 91330-002 E-mail:jmauro@edu.unisinos.br

\section{Arlindo Nonato Morais de Souza} Mestre em Ciências Contábeis pela Universidade Federal do Rio Grande do Norte (2019), docente na Universidade Federal do Rio Grande do Norte. Endereço: Campus Universitário, Av. Salgado Filho, 59078-900, Natal - RN. E-mail: arlindononato@ufrn.edu.br

\section{Yuri Gomes Paiva Azevedo}

Doutorando em Controladoria e Contabilidade pela Faculdade de Economia, Administração e Contabilidade de Ribeirão Preto da Universidade de São Paulo. Mestre em Ciências Contábeis pelo Programa de Pós-Graduação em Ciências Contábeis da Universidade Federal do Rio Grande do Norte (2018). Endereço: Campus Universitário Avenida Bandeirantes, 3900, Vila Monte Alegre, Ribeirão Preto - SP, 14040-905. E-mail: yuriazevedo@usp.br

\section{Aneide Oliveira Araújo}

Doutora em Ciências Contábeis pela Universidade de São Paulo (2001). Professora Titular Aposentada do Departamento de Ciências Contábeis da Universidade Federal do Rio Grande do Norte. Ex-bolsista Capes em Estágio Pósdoutoral na área de sustentabilidade empresarial na Faculdade de Economia da Universidade do Porto, Portugal. Endereco: Campus Universitário, Av. Salgado Filho, 59078-900, Natal - RN. E-mail: aneide.ufrn@gmail.com

\section{Diogo Henrique Silva de Lima} Possui graduação em Ciências Contábeis pela Universidade Federal do Rio Grande do Norte (2004). Mestrado em Ciências Contábeis pela Universidade de Brasília (2007) e Doutorado em Ciências Contábeis pela Universidade de Brasília (2012) . Atualmente, é professor adjunto da Universidade Federal do Rio Grande do Norte (UFRN). Endereço: Campus Universitário, Av. Salgado Filho, 59078-900, Natal - RN. E-mail: diogoh4@ufrnbr 


\section{INTRODUÇÃO}

A forma tradicional como a educação é promovida nos cursos de contabilidade, no geral, não tem sofrido alterações significativas ao longo do tempo (PINCUS et al., 2017), sendo, predominantemente, os educadores os transmissores de informação, de forma narrativa, do conhecimento para os educandos, que mecanicamente são ouvintes passivos e funcionam como depositários (MOILANEN, 2017).

Nessa perspectiva, verifica-se que os educadores têm utilizado métodos passivos de aprendizagem em cerca de $50 \%$ das aulas e que mais de $15 \%$ do tempo é utilizado com atividades de avaliação, ficando $35 \%$ destinado à aprendizagem de forma ativa (BLANKLEY; KERR; WIGGINS, 2017).

Corroborando os resultados obtidos através das respostas dos educadores, Blankley et al. (2017) e Moilanen (2017) destacam que a maioria dos alunos de contabilidade, quando fazem descrições sobre o modelo de aprendizagem que lhes são ofertados, descrevem aspectos de aprendizagem reprodutiva.

Essa caracterização da educação como "bancária" faz com que os educandos passivamente posicionados no processo de aprendizagem não sejam seres de transformação, e sim de adaptação àqueles conteúdos, programas e didáticas que lhes são impostos, aprendendo como espectadores e sendo mantidos ingênuos e, por isso, essa forma de educação recebe críticas (FREIRE, 1987).

Analisando as técnicas e metodologias de ensino como inovações, sob a perspectiva da Teoria da Difusão da Inovação, proposta por Rogers (2003), verifica-se que uma inovação para ser difundida precisa essencialmente apresentar aspectos relacionados à: vantagem relativa, compatibilidade, complexidade, "experimentabilidade" e "observabilidade". Na história do desenvolvimento de sua Teoria, Rogers (2003) destaca a magnitude de sua aplicação à pesquisa em educação, evidenciando a aplicabilidade dos aspectos necessários para a difusão de práticas nessa área.

Nessas circunstâncias, existe uma busca pela melhoria contínua da forma como se ensina, cada vez mais focada em trazer o educando para a participação ativa no processo educativo. Um dos direcionadores deste processo é fazer com que o aluno se torne crítico e independente, para que possa ter argumentos para discutir e solucionar problemas além daqueles que são transmitidos de forma oral pelo educador. Muito embora o sucesso da promoção da aprendizagem ativa não dependa unicamente da metodologia aplicada, esta detém a sua importância no processo (KANE, 2004).

Nessa congruência, dentre o rol das metodologias ativas, o Método de Ensino Baseado em Casos possui destaque em cursos relacionados ao ambiente de negócios, como na Harvard Business School. Além dessa, o método de aprendizagem baseada em casos é amplamente utilizado em múltiplas áreas de conhecimento, como ciências sociais, enfermagem, assistência médica, entre outros, possibilitando que os educandos apliquem os conhecimentos à prática, pratiquem as habilidades de tomada de decisão, utilizem diferentes pontos de vista para analisar diferentes ideias, por diferentes perspectivas (POPIL, 2011).

Os casos para ensino descrevem situações e problemas realísticos e suficientemente complexos que possuem múltiplas decisões hábeis para solucionar problemas, engajando os estudantes a problemas do "mundo real”, promovendo boas discussões em busca do entendimento sobre qual seria a melhor decisão a ser tomada para solucionar os problemas propostos no caso. Em razão desses pontos, o Método de Caso faz com que a aprendizagem centrada no aluno seja, por muitas vezes, claramente superior aos métodos tradicionais (GRUPE; JAY, 2000).

Assim, considerando a inquietação sobre a forma tradicional de aulas expositivas, demonstrada pela busca docente por metodologias que tornem os alunos mais ativos e participantes do processo de construção do conhecimento, aproximando-os da prática profissional ainda no âmbito acadêmico; surge a seguinte questão de pesquisa: à luz da difusão da inovação, como os atributos relacionam-se aos benefícios e às limitações da utilização do Método do Caso?

Nesse sentido, o estudo tem por objetivo examinar como os benefícios e as limitações da utilização do Método do Caso relacionam-se aos os atributos de difusão da inovação. O estudo foi realizado sob a ótica dos discentes e dos docentes que participaram de intervenções educativas com a utilização do Método do Caso. Assim, espera-se notabilizar aspectos relacionados aos elementos-chave da Teoria da Difusão da Inovação: compatibilidade, complexidade, aplicabilidade e "observabilidade", por meio da apresentação e discussão de intervenções educativas realizadas em disciplinas comuns às grades curriculares dos cursos de contabilidade e administração.

Estudos anteriores sobre a temática têm se concentrado em discutir aspectos práticos de operacionalização (e.g., MOSKOVITZ, 1992; HASSALL; LEWIS; BROADBENT, 1998; BRUNER et al., 1999; BOYCE et al., 2001; SOUZA; MARION, 2001) e efetividade do método (BÖCKER, 1987), dessa forma, a presente pesquisa se distingue das referidas pesquisas anteriores por trazer a abordagem do Método do Caso sob a ótica dos discentes e docentes, destacando aspectos relacionados a benefícios e limitações, conforme proposto no objetivo supramencionado.

É esperada uma contribuição prática no sentido de os resultados fornecerem aspectos que podem ser observados para o melhoramento das formas com as quais é comumente realizado o processo educativo nos cursos de contabilidade e administração. Em relação à contribuição para a literatura, a presente pesquisa avança na abordagem de como o Método do Caso pode ser discutido como inovação metodológica à luz da Teoria da Difusão da Inovação.

O trabalho está estruturado em cinco seções: esta primeira, que contextualiza a questão de pesquisa e apresenta o objetivo; a segunda apresenta o referencial teórico, trazendo aspectos relacionados às metodologias ativas de ensino, o Método do Caso e a Teoria da Difusão da Inovação; a terceira descreve os procedimentos metodológicos adotados; a quarta apresenta os resultados obtidos e a discussão desses e a quinta trata das considerações finais. 


\section{REFERENCIAL TEÓRICO}

\subsection{Metodologias Ativas de Ensino}

No âmbito da melhoria contínua do ensino, existe uma busca para tornar os ambientes e os participantes mais ativos, de forma a incentivar a independência e a criticidade dos alunos e provocar discussões e soluções para sair de um ambiente onde a técnica pedagógica seria a de transmissão de conhecimento pelo docente para um totalmente centrado no aluno (KERN, 2002; KANE, 2004; CHERNEY, 2008; CHI, 2009).

Embora conceitualmente as metodologias ativas de ensino possam ser ambíguas (KANE, 2004), a aplicação de ferramentas e técnicas pedagógicas para o ensino com abordagens sobre a resolução de problemas práticos é latente e efetiva para a melhora da aprendizagem propriamente dita. Tal fato está sob o enfoque de trazer o aluno para a participação ativa no processo de aprendizagem.

A aplicação das metodologias ativas tem apresentado importantes resultados no que se refere à sua aplicação no curso de Ciências Contábeis, no sentido de melhorar o desempenho dos participantes nas disciplinas (GUERRA; TEIXEIRA, 2016). Muito embora essas metodologias exijam dos participantes do processo de ensino-aprendizagem mais comprometimento e carga de trabalho, os resultados são perceptíveis, o que se deve aumentar é o cuidado em relação à sobrecarga às partes que estão relacionadas nesse processo (CITTADIN et al., 2015).

Diferentemente dos métodos tradicionais de ensino-aprendizagem em que o discente é compreendido como a parte passiva, nas metodologias ativas, esse atua diretamente no processo de construção do conhecimento, sendo o professor o mediador e potencializador do processo de aprendizagem. Assim, o envolvimento do docente é fator determinante para o sucesso da aplicação efetiva e eficiente das metodologias ativas (ADLER; WHITING; WYNN-WILLIAMS, 2004; KANE, 2004).

O estímulo ao aluno é indubitavelmente um fortalecedor da prática do estudo para que se possa tentar resolver os problemas, o que fortalece a interação social e o senso de compromisso, uma vez que o torna parte formadora do conhecimento. No entanto, é preciso ser evidenciado que nem sempre o aluno está preparado para efetivamente se tornar essa parte (MARIN et al., 2010).

Contudo, Blankley et al. (2017) destacam que grande parte do tempo de sala de aula ainda é utilizado com metodologias passivas (50\%), embora já tenha se passado mais de vinte anos da criação da Accounting Education Change Commision (AECC), que tem como um dos seus objetivos modificar a forma como se ensina contabilidade, sendo discutida a inserção das metodologias ativas nas disciplinas dos cursos de graduação.

Dentro do rol de técnicas utilizadas para implementar a aprendizagem ativa, é possível destacar a aprendizagem baseada em casos, método esse que visa aproximar o estudante da prática de mercado por meio da aprendizagem com base em casos reais (BROWN; GUPTA, 1994; BROWN; FOSTER, 1995; BOYCE et al., 2001; SOUZA; MARION, 2001; WEIL; OYELERE; RAINSBURY, 2004; APOSTOLOU et al., 2016; MINNITI et al., 2017; MOILANEN, 2017).

\subsection{Método do Caso}

O ensino baseado em caso requer alguns atributos tanto do aluno como do docente, que deve atuar como mediador nesse método de ensino-aprendizagem. Bruner et al. (1999) evidenciam que, primeiramente, é necessário que o docente tenha o discernimento de escolher casos hábeis que tenham o emprego, o exercício ou a exploração de uma ferramenta ou um conceito. Além disso, é basilar o destaque dos dilemas inerentes à decisão que o estudante pode tomar, como também às possíveis implicações que permeiam aquele caso específico.

A utilização de casos reais é vista como uma oportunidade de aplicação de conceitos e conhecimento em situações do mundo real, onde a mutabilidade proporciona o desenvolvimento, mesmo se tratando de uma retratação de uma situação real. Assim, essa utilização em um ambiente de ensino deve proporcionar liberdade de escolha de decisões ao estudante, para que use os seus julgamentos e ache possíveis soluções para o problema com a aplicação da teoria.

Souza e Marion (2001) apresentaram uma abordagem inicial sobre a utilização do Método do Caso, demonstrando o que é um caso para ensino, mostrando que, por algumas vezes, exemplos ou "historinhas" são erroneamente entendidos como casos. Corroborando essa abordagem, Zhang, Liu e Chen (2014) elucidam que existe uma confusão por parte dos docentes quando utilizam os casos como metodologia de ensino, pois, muitas vezes, por uma compreensão errônea da ferramenta, os casos são utilizados como uma exemplificação do conteúdo.

A aprendizagem baseada em casos é, dentre tantas, uma das formas de interação entre o aluno e o professor no processo de construção do conhecimento. Sua utilização é ampla e depende bastante do envolvimento dos participantes nas proposições para resolução do caso, inclusive possibilitando o confronto de opiniões de outro proponente, sendo que não é condição pressuposta a existência de uma resposta certa ou errada para o caso.

Segundo Morrison (2001), todos os casos para ensino causam um reflexo no modelo de aprendizagem daqueles que participam dessa metodologia. A partir dessa perspectiva, flui naturalmente um modelo de ensino de acordo com a intencionalidade com a qual o caso foi elaborado. Este modelo pode ser visualizado na Figura 1: 
Figura 1 - Estrutura da aprendizagem baseada em casos

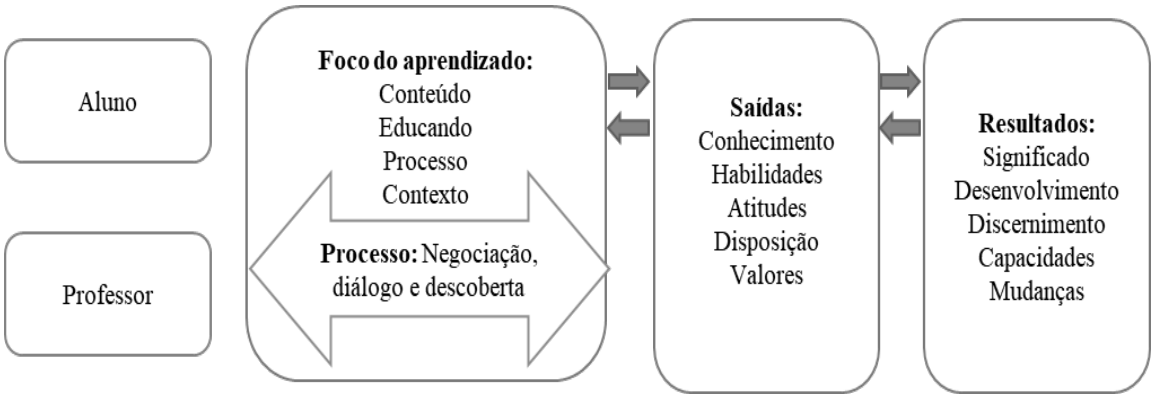

Fonte: Traduzido e adaptado de Morrison (2001)

A aprendizagem baseada em casos para ensino tem seu potencial subutilizado da forma como é conduzida, muito embora já colabore para diminuir a lacuna presente entre a teoria e a prática contábil (CULLEN; RICHARDSON; BRIEN, 2004). Esse contexto é corroborado por Moilanen (2017), ao trazer que a utilização do Método de Caso faz com que o aluno aprimore a aplicação dos conhecimentos na vida real, sendo que esse ponto requer atenção especial voltada à forma como é feita a aplicação. Essa utilização pode ser feita com alunos nos mais diversos níveis, desde níveis iniciais até avançados (BAYONA; CASTAÑEDA, 2017).

Dentre as pesquisas presentes na literatura, é possível notar que algumas são consideravelmente descritivas e teóricas e têm um aspecto mais voltado ao embasamento da potencialidade do método em si do que um experimento propriamente dito (e.g., BÖCKER, 1987; MOSKOVITZ, 1992; HASSALL; LEWIS; BROADBENT, 1998; BRUNER et al., 1999; BOYCE et al., 2001; SOUZA; MARION, 2001). Essas investigações definem conceitos importantes inerentes ao método e à sua aplicação como uma metodologia ativa de ensino.

No delineamento da aprendizagem baseada em casos, Hassall et al. (1998) listam algumas habilidades que são necessariamente primordiais ao estudante que se propõe a aprender por esse método, podendo destacar principalmente a aquisição prévia de conhecimento acerca do tema cujo caso está inserido para que, assim, esse conhecimento possa ser aplicado à resolução de um problema. A utilização da aprendizagem baseada em casos proporciona, ainda, o desenvolvimento de habilidades como: (i) desenvolvimento do trabalho em grupo, (ii) habilidade de realizar, individualmente, pesquisas fora de sala de aula, (iii) coleta e análise de informações em fontes diversificadas, (iv) gestão de tempo, (v) habilidades de apresentação, e (vi) habilidades práticas (LEAL; MEDEIROS; FERREIRA, 2017).

Como é intuitivamente pressuposto para a aplicação de um caso de ensino, é necessária a apresentação do caso em si. Em resumo, o caso se trata de uma situação preferencialmente real de descrição de um problema, bem como de todo o contexto subjacente a esse e, por fim, algumas aplicações conceituais, questionamentos para gerar discussões e as perspectivas futuras que são vistas no ambiente de ocorrência do caso.

\subsection{Teoria da Difusão da Inovação}

Considerando que as metodologias ativas de ensino podem ser vistas como inovações em comparação com as metodologias tradicionais de ensino, tem-se a Teoria da Difusão da Inovação que, de acordo com Rogers (2003), destaca a magnitude de sua aplicação à pesquisa em educação, demonstrando a aplicabilidade dos aspectos necessários para a difusão de práticas nesta área.

Dentre os primeiros trabalhos que trataram sobre a aceitação e difusão de inovações, é relevante destacar o desenvolvimento investigativo de Ryan e Gross (1950, que investigaram aspectos que fazem uma inovação ser aceita, ou não, a partir de um fenômeno, à época que foi a difusão da utilização das sementes híbridas de milho no sul de Iowa.

A partir dessa investigação, Rogers (2003) iniciou, em sua primeira publicação, um trabalho contínuo de entendimento e aperfeiçoamento do que é hoje entendido e conhecido como os aspectos que exercem influência sobre a difusão, entendida no sentido de propagação, de uma inovação.

Dentre os atributos que caracterizam uma inovação, citam-se a vantagem relativa, a compatibilidade, a complexidade, a "experimentabilidade" e a "observabilidade". A vantagem relativa é, basicamente, o quanto a inovação é percebida como melhor que a prática que ela substitui; a compatibilidade é o quanto a inovação é consistente com as práticas e o ambiente habitual; a complexidade refere-se a quão difícil é entender e utilizar a inovação; a "experimentabilidade" está relacionada à mudança gradativa; e a "observabilidade" possui elo com os resultados obtidos e como eles podem ser vistos (ROGERS, 2003).

Em educação, considerando as inovações, sejam tecnológicas ou no formato das aulas, não é diferente. Ahmed, Daim e Basoglu (2007) destacam aspectos e resultados empíricos sobre o processo de implantação de sistemas de informações na educação superior, demonstrando que segue a mesma dependência de atributos que outros tipos de inovação.

Ainda em práticas de intervenções educativas, Avdagovska et al. (2016) oferecem insights e Murimi et al. (2017) reconhecem a difusão como um fator que influência na eficácia das intervenções educativas. Já Caliari, Zilber e Perez 
(2017) utilizam da Teoria da Difusão da Inovação para entender quais variáveis influenciam a adoção de ferramentas educacionais na educação superior presencial.

Embora os cinco atributos propostos por Rogers (2003) sejam reconhecidamente importantes para determinar a difusão ou não de uma inovação, eles não são, por si só, exaustivos. Dessa forma, Caliari et al. (2017) destacam mais alguns atributos, que também não exaurem o rol de atributos que são idiossincráticos. São eles: a imagem, o uso voluntário e a visibilidade.

\section{ASPECTOS METODOLÓGICOS}

Em virtude da essência do problema de pesquisa, a presente investigação possui características que a enquadram na utilização do método de pesquisa qualitativo, conforme a classificação de Angrosino (2009), tendo como unidade de análise do estudo de caso: (i) discentes de graduação dos cursos de contabilidade e administração; bem como (ii) dois docentes dos cursos de administração e contabilidade.

A realização das intervenções educativas nas turmas de graduação com a utilização do Método de Caso foi antecedida pela realização de um estudo piloto com uma turma de mestrado em Contabilidade, composta por onze alunos que cursavam a disciplina de Metodologia do Ensino Superior, que tem como objetivo a apresentação, a discussão e a implementação de metodologias ativas.

O objetivo da realização do estudo piloto foi realizar uma aplicação prática utilizando o Método de Caso e, após essa aplicação, realizar um grupo focal com os participantes para debater quais os prós, os contras e as limitações do método e do caso aplicado para, assim, proceder com os ajustes e efetuar as demais aplicações nas turmas de graduação.

Sendo assim, a aplicação anterior na turma de mestrado teve por objetivo validar e discutir as ferramentas e como o método deveria ser utilizado, mitigando possíveis inconsistências. Para tanto, foram retiradas, de forma intencional, as notas de ensino dos referidos casos. Nessa intervenção educativa, os alunos do mestrado que foram submetidos à aplicação da metodologia já haviam estudado sobre os conhecimentos que dariam suporte à resolução e ao debate dos casos apresentados.

Após a intervenção educativa, as discussões promovidas no grupo focal realizado com os participantes resultaram em um rol de possiblidades de aplicações para os casos utilizados. Dentre os possíveis aspectos a serem abordados, destacaram-se os conteúdos sobre modelos de gestão, consultoria empresarial, análise de investimentos, análise das demonstrações, controladoria, planejamento tributário e finanças.

No tocante ao grupo focal, ressalta-se que esse foi realizado apenas na turma de mestrado em Ciências Contábeis, como parte da aplicação do estudo piloto, tendo como base uma pergunta aberta inicial sobre a percepção dos mestrandos acerca dos benefícios, do papel do docente, das limitações da metodologia aplicada e das possibilidades de aplicação dos casos posteriormente nas turmas de graduação, sendo assim, as evidências obtidas nessa aplicação subsidiaram tão somente o refinamento e direcionamento das aplicações nas turmas de graduação.

Após as discussões e a aplicação do estudo piloto, foi realizada a aplicação da metodologia nas turmas de graduação. De forma a tentar evitar o estranhamento da metodologia pelos educandos que fizeram parte das intervenções, foi exposto que os casos a serem discutidos não apresentavam uma resposta única que pudesse ser tida como correta, e, dessa forma, todos deveriam propor soluções para que pudesse fluir um debate. Foi evidenciado que tal discussão seria imprescindível para se maximizar o objetivo da utilização do Método do Caso. Foi dito, ainda, que os aspectos conceituais que subsidiariam as soluções seriam aqueles já trabalhados no decorrer das disciplinas em aulas anteriores.

O caso para ensino aplicado na turma de graduação em contabilidade foi o intitulado "Caminhos da Viação Nordeste LTDA” (SILVEIRA et al., 2017). Nessa turma, procedeu-se à aplicação do referido caso durante a disciplina Controladoria Empresarial, tendo em vista que os aspectos trabalhados no caso encontram-se no escopo da referida disciplina, apesar de serem temas interdisciplinares.

A outra turma na qual o presente estudo também aborda a aplicação do Método do Caso é uma turma do curso de graduação em administração. Nesse grupo, foi aplicado, na disciplina de Marketing, o caso proposto por Soares, Silva e Machado (2014), intitulado “Os chineses estão chegando! O que fazer com meu marketing mix?”.

O critério para seleção das referidas turmas foi o de conveniência e acessibilidade. Os docentes responsáveis pelas turmas consentiram permissão para que os discentes do mestrado realizassem os procedimentos metodológicos, tanto de aplicação das intervenções, como de coleta de evidências. Entretanto, ressalta-se que os discentes de mestrado que aplicaram o caso não tinham qualquer vínculo com os discentes da graduação que receberam as intervenções.

Em relação à coleta de evidências, dentre o rol de técnicas e ferramentas apresentadas por Flick (2009), foram escolhidas, além da discussão em grupo focal, a observação participante, a aplicação de questionários e a realização de entrevistas como forma de construção de evidências acerca da percepção dos discentes e docentes participantes sobre a implementação e aplicação do Método de Caso. A Figura 2 apresenta o fluxo dos procedimentos realizados na presente pesquisa, desde o planejamento, até a coleta das evidências: 
Figura 2: Fluxo dos procedimentos metodológicos adotados

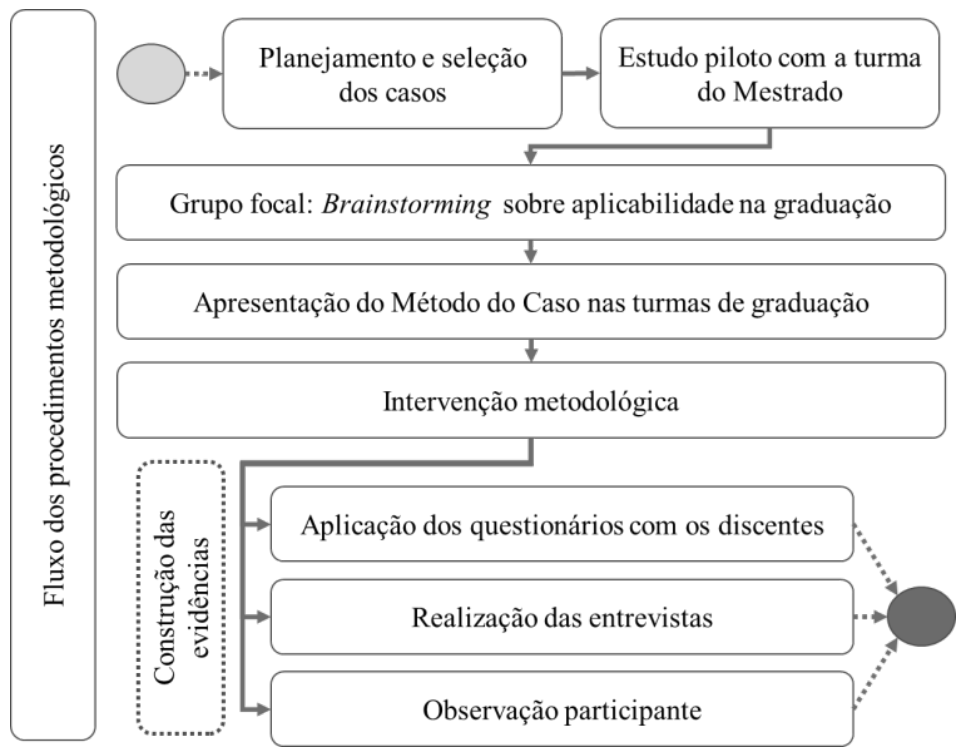

Fonte: Elaborado pelos autores

A observação foi motivada para se tomar notas das aplicações, a fim de examinar possíveis contrapontos em relação aos questionários e entrevistas realizadas. Os questionários semiestruturados foram aplicados aos discentes das turmas pesquisadas, sendo trazidas perguntas propostas por Morrison (2001), além de outros quesitos visando a obtenção de informações acerca dos discentes participantes das intervenções educativas.

As perguntas estão sumarizadas na Figura 3, de acordo com o seu elo com o elemento-chave da Teoria da difusão da inovação.

Figura 3 - Quesitos do instrumento de pesquisa e elementos-chave da Teoria da difusão da inovação

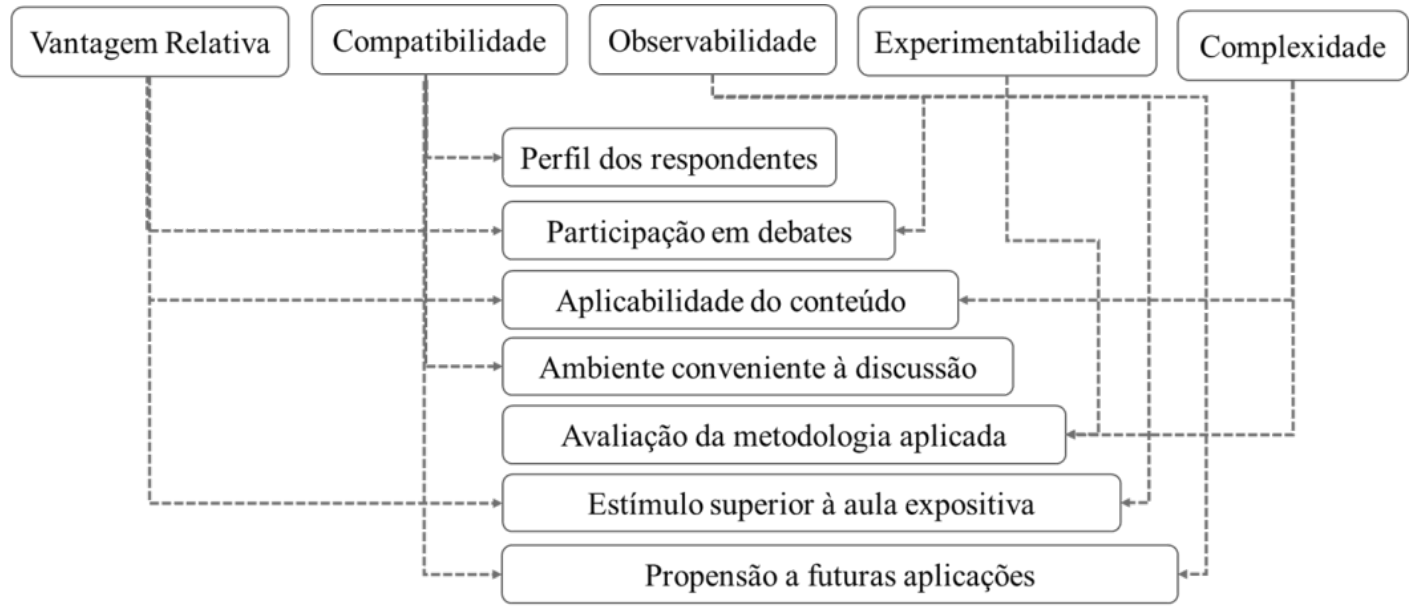

Fonte: Elaborado pelos autores

As entrevistas foram realizadas com os docentes responsáveis pelas disciplinas que receberam as intervenções com o Método do Caso. No roteiro das entrevistas, constavam perguntas abertas relacionadas à: (i) experiência docente e utilização de metodologias ativas, (ii) percepção quanto a vantagens do Método de Caso em relação à tradicional aula expositiva, (iii) compatibilidade metodológica da intervenção com as disciplinas lecionadas pela docente no que tange a aspectos relacionados à compreensão do método por parte dos discentes, (iv) importância de utilizar metodologias ativas em outras disciplinas, bem como (v) as dificuldades encontradas na aplicação do método. 
Após a aplicação dos questionários, bem como após a realização do grupo focal e as entrevistas, os dados coletados foram tabulados em planilhas eletrônicas e as evidências obtidas por meio das entrevistas foram transcritas para posterior codificação e análise realizada por meio do software Atlas.ti @. Os dados foram pré-analisados e, após a exploração do material para ser interpretado, foi realizada a análise dos dados descritivos e de conteúdo, seguindo as diretrizes para análise de conteúdo evidenciadas por Bardin (2011).

\section{RESULTADOS}

\subsection{Perfil dos respondentes}

Os participantes das intervenções são alunos de graduação em Administração e Ciências Contábeis, totalizando 46 discentes. Dividindo a amostra por gênero, verifica-se que 26 dos 46 respondentes (56,52\% da amostra) são do gênero masculino e os demais 20 participantes (43,48\% da amostra) são do gênero feminino. Quanto à idade, procurou-se identificar a idade dos participantes, com grupos de "18 a 22 anos”, "23 a 27 anos”, "28 a 35 anos" e "acima de 35 anos”. Observa-se que a maioria são jovens, sendo $91,30 \%$ da amostra composta por pessoas com menos de 35 anos.

\subsection{Resultados das intervenções educativas}

A partir da observação dos alunos por parte dos pesquisadores ao longo das intervenções educativas, percebeu-se uma melhora, com alguns destaques na participação deles nas discussões, o que corrobora o resultado obtido em relação a esse ponto na aplicação dos questionários. Assim, foi verificado que a maioria dos alunos se sentiu mais propensa a participar das discussões em sala, como é observado na Tabela 1. Nos questionários aplicados, os respondentes selecionavam um valor em uma escala, sendo que, quanto mais próximo de 7, maior concordância o respondente apresenta com a afirmativa em questão.

Tabela 1- Estímulo ao debate

\begin{tabular}{c|c|c}
\hline $\begin{array}{c}\text { Me senti mais propenso a } \\
\text { participar dos debates }\end{array}$ & Quantidade de individuos & Frequência \\
\hline 0 & 2 & $4,35 \%$ \\
1 & 2 & $4,35 \%$ \\
2 & 1 & $2,17 \%$ \\
3 & 3 & $6,52 \%$ \\
4 & 7 & $15,22 \%$ \\
6 & 8 & $17,39 \%$ \\
7 & 11 & $23,91 \%$ \\
\hline
\end{tabular}

Fonte: Dados da pesquisa

Partindo do observado empiricamente e pressuposto pela literatura de que os participantes deste estudo estavam acostumados a receber metodologias não ativas na maior parte do tempo (BLANKLEY; KERR; WIGGINS, 2017; MOILANEN, 2017), em comparação com a aula expositiva, os discentes afirmaram estarem mais estimulados com a aplicação do Método de Caso. Este resultado encontrado corrobora as evidências de Cittadin et al. (2015), em virtude da necessidade de maior comprometimento e participação quando o educando se encontra no polo ativo da aprendizagem. Este resultado está evidenciado na Tabela 2. 
Tabela 2 - Comparação com a aula expositiva

\begin{tabular}{c|c|c}
\hline $\begin{array}{c}\text { A aplicação do Método de Caso me } \\
\text { estimulou mais que a aula expositiva }\end{array}$ & $\begin{array}{c}\text { Quantidade de } \\
\text { indivíduos }\end{array}$ & Frequência (\%) \\
\hline 0 & 2 & $4,35 \%$ \\
1 & 2 & $6,52 \%$ \\
2 & 3 & $15,22 \%$ \\
3 & 7 & $13,04 \%$ \\
4 & 6 & $13,04 \%$ \\
6 & 6 & $17,39 \%$ \\
7 & 8 & $26,09 \%$ \\
\hline
\end{tabular}

Fonte: Dados da pesquisa

Os resultados sumarizados nas Tabelas 1 e 2, que são as perguntas ligadas ao elemento-chave "vantagem relativa" demonstram que esse atributo é percebido pelos participantes, tanto docentes como discentes. Ainda que mais distribuídos que o resultado sobre a propensão ao debate, os resultados desta pesquisa podem ser suficientes para qualificar que, nas intervenções, o Método do Caso obteve vantagem como inovação em relação ao tradicionalmente apresentado aos respondentes (aula expositiva). Tal ponto é evidenciado também pelos docentes entrevistados, conforme o trecho relatado na entrevista:

\begin{abstract}
"Porque eu diria que a grande vantagem é preparar o aluno para o entendimento de um caso. No caso de decisão, e o gestor é um decisor, e que o decisor ele está ali com uma série de dados, então mostra ao aluno que em qualquer decisão eu tenho que ter o suporte dos dados, e o caso para ensino teria essa vantagem de além de deixar o aluno menos tenso, mais preparado, entendendo que prática e teoria são próximos, não são distintos, a teoria foi construída numa outra prática mas pode ser ajustada para outras realidades (informação verbal)."
\end{abstract}

Conforme o trecho transcrito, o docente responsável pela turma no curso de administração evidencia de forma enfática que o método prepara o aluno ao trazer situações reais de tomada de decisão para a aplicação dos conceitos por ele ministrados em sala de aula. Tal atributo foi evidenciado por este entrevistado como sendo a principal vantagem do método em relação à tradicional aula expositiva. Sendo assim, foi direcionado como atributo "vantagem relativa", de acordo com a teoria da difusão de Rogers (2003).

Corroborando com o percebido empiricamente pelo primeiro entrevistado, o segundo entrevistado afirma que percebe que o método aproxima o discente das práticas que ele vivenciará no mercado, trazendo o ambiente real de tomada de decisão para a sala de aula e desmitificando que a prática diverge dos conceitos aprendidos em sala de aula.

Sendo assim, este entrevistado também aponta como principal atributo de vantagem relativa em relação à aula expositiva: o estímulo para o discente buscar e filtrar quais informações são hábeis para tomar a decisão e solucionar o problema exposto, diferente do que acontece normalmente nas aulas expositivas. A transcrição da fala da entrevista que ilustra esta evidência é trazida no seguinte trecho:

\footnotetext{
"Acredito que uma das principais vantagens do Método de Caso é aproximar o discente da prática empresarial, uma vez que simula um ambiente de tomada de decisão com informações desestruradas. Dessa forma, o estudante sai da zona de conforto, pois precisa raciocinar, de forma crítica, para filtrar as informações necessárias para a resolução do caso, diferentemente de exercícios tradicionais, em que todas as informações disponibilizadas normalmente são utilizadas na sua resolução (informação verbal). "
}

As evidências obtidas através das entrevistas com os docentes indicam que a habilidade destacada por Leal, Medeiros e Ferreira (2017), de que o método do caso proporciona o desenvolvimento de habilidades práticas, é percebida pelos docentes como uma das principais vantagens do Método do Caso.

No tocante às perspectivas dos discentes, quando questionados sobre de que forma eles se sentiriam mais propensos a participarem das discussões em sala, as respostas mais latentes foram relativas à dinâmica da aplicação, a participação nos debates, a praticidade do caso e o papel do professor na sala de aula. Se tratando de uma metodologia ativa de ensino, os discentes frisaram que a aplicação do Método de Caso deve ser dinâmica e envolvente, o que pode configurar, pelo observado, uma aceitação da inovação metodológica pela maior parte dos discentes. Para ilustração desta percepção, seguem os seguintes trechos das respostas: 
"Se as aulas abordassem esse tipo de metodologia mais dinâmica (Participante 30). Se todos os colegas se comprometessem com o desenvolvimento do trabalho (Participante 31)."

No entanto, de acordo com a observação realizada na pesquisa, pôde-se perceber que ainda que estimulados, alguns alunos não demonstravam interesse em fazer com que a aula se tornasse mais dinâmica. Nas turmas de graduação, após a aplicação da metodologia do caso, notoriamente existiu uma melhora neste fator, ainda de forma mais intensa no segundo momento de aplicação da metodologia. Este resultado pode ser visto como uma comprovação de que a inovação metodológica aplicada fez com que os alunos se sentissem mais estimulados a participar da aula.

Esta evidência está de acordo com a abordagem destacada por Leal, Medeiros e Ferreira (2017) de que a utilização do método de caso desenvolve habilidades de trabalho em grupo, em que pese os discentes interagirem entre si e compartilharem com o grupo seus conhecimentos e experiências pessoais. Sendo a participação uma habilidade importante para que a aprendizagem baseada em casos seja efetiva pela discussão (MORRISON, 2001), a participação no debate foi destacada pelos alunos, conforme destacado pelos discentes 1 e 15 do curso de administração no trecho a seguir:

"Eu já sou participativo. Os professores jogando debates para os alunos ou executando atividades para posterior discussão aumentam a participação do discente (Participante 1). Esse momento fosse mais aberto e incentivado na aula (Participante 15)."

No entanto, parte dos discentes afirmou que participariam mais conforme a qualidade do debate, evidenciando pontos que as aulas ministradas ao longo da graduação tivessem uma maior abertura para o debate, e, consequentemente, a expressão de suas opiniões foram:

"Se as aulas fossem mais voltadas para a participação (Participante 4). Se pudesse expressar a minha opinião em determinado assunto (Participante 11). Esse momento fosse mais aberto e incentivado em aula (Participante 15). Se fosse uma prática mais habitual (Participante 35).”

Examinou-se também a importância da tangibilidade do tema pelos alunos, apresentando a necessidade de aplicação de casos de empresas regionais, onde os alunos pudessem enxergar melhor os problemas expostos, além da praticidade do caso, ligando diretamente o caso de ensino com os assuntos abordados em sala. Este aspecto está relacionado à compatibilidade e complexidade destacada por Rogers (2003) como aspectos decisivos para aceitação de uma inovação. A respeito disso, os discentes evidenciaram os seguintes trechos:

"Se existisse mais contextualização dos assuntos abordados (Participante 12). Se existisse um direcionamento do conteúdo para aplicabilidade em caso prático. Antes de começar a aplicação do método (Participante 14). Acho que se tivesse sido disponibilizado mais informações sobre a empresa e sobre o contexto que a mesma estava inserida chamaria mais a atenção dos discentes (Participante 29)."

Dessa forma, a utilização da metodologia do caso estaria ligada diretamente à consolidação do conhecimento previamente adquirido nas aulas expositivas, sendo possível a sua utilização como forma de trazer a aplicação prática dos conhecimentos adquiridos em sala de aula, desmistificando a falácia de que a prática é totalmente divergente dos aspectos conceituais e teóricos estudados em sala de aula, conforme evidenciado pela entrevistada no trecho:

"Eu tenho disciplinas de Marketing, Finanças, etc. E aí o aluno acha, eu percebo isso, que o aluno vê algumas teorias, que ele acha que porque é teoria, que aquilo ali não é muito aplicado. Mas quando ele vê, e o professor leva a teoria e o caso antes ou depois, ele vai ver e vai dizer: não, espera aí, a teoria que eu estou estudando aqui, está sendo aplicada em uma empresa, por um gestor (informação verbal)."

Na percepção dos discentes, estes ainda destacaram o papel do professor na condução da aplicação do caso para ensino, evidenciando como este poderia auxiliar em um melhor aproveitamento do caso por todos no debate. O trecho que ilustra esta dimensão é o seguinte:

"Eu participo bastante, mas para alunos mais tímidos é necessária uma integração da turma toda, para ele se sentir integrado (Participante 22). Acho que se tivesse sido disponibilizado mais informações sobre a empresa e sobre o contexto que a mesma estava inserida chamaria mais a atenção dos discentes (Participante 27).”

No entanto, ressalta-se que as metodologias ativas de ensino possuem um certo nível de desestruturação, e com o Método de Caso isto não é diferente. Assim, essa perspectiva pode ser verificada possivelmente pelo fato de o discente não ter tido contato com estas metodologias no decorrer da graduação. Um trecho elucidativo sobre esta questão é apresentado por um discente que afirma que se sentiria mais propenso a participar se "fosse questionado perguntas a respeito do que estou aprendendo (Participante 39)." 
Contudo, pela observação e pela análise do conteúdo das respostas pôde-se perceber que embora estimulados, alguns alunos não correspondem aos estímulos, o que pode expor que no momento inicial a inovação aplicada é recebida com estranheza e provoca a aversão de alguns educandos que preferem estar passivos no processo educacional, ou demonstram pouco interesse, comprovado por afirmativas do tipo: "se eu soubesse do assunto" ou "se todos da sala participassem".

De acordo com este resultado é possível traçar um elo entre a falta de visibilidade do caso para ensino, num momento inicial, como uma situação real de problema que pode e deve ser resolvida pelo discente com o intuito de construir o conhecimento através daquela prática. Esta falta de consciência é, para a entrevistada, um motivo de desestímulo para o docente que busca inovações no sentido de melhorar a aprendizagem. O trecho da entrevista transcrito a seguir ilustra este ponto:

“[...] Ele não entende ainda mesmo que a gente diga, ele não entende o real valor de um caso. Isso empiricamente eu percebo, é como se eles vissem ali o caso, não nem todos, mas eu vejo um grupo de alunos muito comprometidos, geralmente quanto mais o aluno (empiricamente eu também percebo) vai para uma pós-graduação Lato Sensu ou Stricto Sensu ele entende que ali foi fruto de uma construção muito consistente."

Nesta congruência, pela ótica da educadora entrevistada, os discentes muitas vezes não conseguem entender a importância e a relevância da utilização de casos para ensino, bem como de outras metodologias ativas, em virtude de um estranhamento, uma vez que ainda existe a prevalência da aula expositiva pelos demais docentes. No entanto, ao conhecer diversificadas metodologias, existe uma quebra de paradigma e por vezes é notório para o aluno que o aprendizado foi melhor.

"Eu noto que o aluno em administração (eu já fiz uma pesquisa sobre isso em turismo), ele não quer que o professor adote só uma metodologia de ensino, eu acho que esse é o problema. [...] Porque em administração eu percebo isso empiricamente e em turismo eu já vi na pesquisa que quer multi, multi estratégias metodológicas, se eu começar a adotar só uma, ou mais uma de que outras eu noto que eles não valorizam (informação verbal)."

A falta de entendimento de que as metodologias ativas produzem resultados favoráveis pode desmotivar os alunos com a aplicação destas, podendo fazer com que os alunos tenham a distorcida visão de que o professor que aplica metodologias ativas é aquele que "não quer dar aula". Ainda que a literatura demonstre que a carga de trabalho para estes profissionais seja mais árdua (CITTADIN et al., 2015). O seguinte trecho da entrevista ilustra este ponto:

\footnotetext{
"Seria interessante [...] vários professores usando a mesma metodologia, vai deixar o aluno com o entendimento que não é só [nome] que está fazendo porque ela não quer dar aula, é um grupo de professores que está preocupado com o ensino deles (informação verbal)."
}

Ainda que perante as limitações encontradas no resultado desta pesquisa, em relação à melhoria na qualidade do aprendizado do educando, na percepção da educadora entrevistada os resultados obtidos com a aplicação de metodologias ativas como o Método de Caso fazem com que ela continue a aplicar a inovação metodológica desde que a conheceu.

Os resultados encontrados corroboram com a contínua difusão da inovação metodológica, uma vez que atende aos quesitos de vantagem relativa, compatibilidade, complexidade, "experimentabilidade" e "observabilidade", em especial no condizente à aplicação prática de conceitos teóricos e de fixação de conteúdo.

A principal vantagem relativa é a aplicação prática de aspectos teóricos; a compatibilidade é evidente pelo relato da entrevistada que julga como aplicável em todas as disciplinas que já ministrou nos seus mais de vinte anos como educadora; complexidade é adequada ao ambiente em que foi experimentado e em razão disso a participação dos educandos foi satisfatoriamente melhor; a "experimentabilidade" é ressaltada pelo tempo em que foram realizadas as aplicações, sendo de duas aulas para a turma de graduação; e a "observabilidade" dos resultados é notória para a melhora da aprendizagem, evidente pela utilização da metodologia desde que foi apresentado à entrevistada.

\section{CONSIDERAÇÕES FINAIS}

O presente estudo objetivou examinar como os benefícios e limitações da utilização do Método do Caso relacionam-se aos os atributos de difusão da inovação. O estudo foi realizado sob a ótica dos discentes e dos docentes que participaram de intervenções educativas com a utilização do Método do Caso.

Conforme os resultados, verificou-se uma boa aceitação e aproveitamento do Método do Caso pelos alunos participantes. Dentre as vantagens percebidas no estudo, destacam-se: possibilidade de uma visão mais holística dos assuntos abordados em sala de aula pelos alunos; alinhamento entre a teoria estudada em sala e a prática no mercado de trabalho; participação ativa dos alunos nas discussões, melhorando a sua capacidade para expor e confrontar ideias.

Os achados obtidos na pesquisa mostraram que a utilização do Método do Caso pode melhorar o processo de aprendizagem e o resultado desta utilização é percebido pelos educadores e educandos. Ainda que num primeiro momento de exposição à nova metodologia exista resistência, os participantes de forma geral demonstram que estão aptos e abertos para novas aplicações. 
Além disso, no que se refere à difusão da inovação metodológica a pesquisa demonstrou que o Método de Caso possui os aspectos suficientes para que seja difundido, que são a vantagem relativa, compatibilidade, complexidade, "experimentabilidade" e "observabilidade".

Os resultados da presente pesquisa vão ao encontro dos resultados já reportados na literatura de que a metodologia frequentemente aplicada é a aula expositiva e que as metodologias ativas evidenciam melhora no processo educativo (KERN, 2002; ADLER; WHITING; WYNN-WILLIAMS, 2004; KANE, 2004; BLANKLEY et al., 2017; MOILANEN, 2017), em sentido focado, o Método de Caso (MOSKOVITZ, 1992; GOLICH, 2000; MORRISON, 2001; SOUZA; MARION, 2001). Em sentido estrito, observou-se que o método exige mais do professor e dos alunos, podendo causar certa aversão quanto à utilização desta metodologia.

As implicações práticas do presente estudo corroboram com a necessidade de melhoramento da forma de consolidação do processo de ensino-aprendizagem, mais especificamente em disciplinas da área de negócios, como as que foram alvo das intervenções metodológicas e geraram os resultados da presente investigação; uma vez que o Método do Caso pode aproximar o discente a desenvolver competências de aplicações práticas de conceitos para solucionar dilemas que lhe serão demandados no mercado de trabalho.

A pesquisa possui limitações de acesso a mais turmas que apliquem o Método de Caso. No entanto, considera-se que isto não acarreta viés, visto que os resultados obtidos não são generalizáveis, até mesmo por não ser objetivo do método qualitativo. Sendo assim, o emprego dos métodos qualitativos tem como foco a profundidade na investigação realizada a partir da triangulação de entrevistas, observação participante, questionários e grupo focal.

A presente metodologia ativa tem amplos campos para pesquisas futuras, entre os quais sugere-se continuar com a triangulação das percepções dos docentes e dos alunos, a fim de melhorar e consolidar o debate sobre a aplicação de metodologias ativas em cursos de Ciências Administrativas, além da sua aplicabilidade em outras áreas do conhecimento, com foco em como os docentes podem melhorar a qualidade do ensino através da aplicação de casos para ensino.

\section{REFERÊNCIAS}

ADLER, R. W.; WHITING, R. H.; WYNN-WILLIAMS, K. Student-led and teacher-led case presentations: empirical evidence about learning styles in an accounting course. Accounting Education, v. 13, n. 2, p. 213-229, 2004.

AHMED, H.; DAIM, T.; BASOGLU, N. Information technology diffusion in higher education. Technology in Society, v. 29, n. 4, p. 469-482, 2007.

ANGROSINO, M. Etnografia e observaçao participante. Porto Alegre: Bookman Editora, 2009. 137 p.

APOSTOLOU, B.; DORMINEYA, J. W.; HASSELL, J. M.; WATSON, S. T. Accounting education literature review. Journal of Accounting Education, v. 39, n. 1, p. 1-31, 2016.

AVDAGOVSKA, M.; BISTRITZ, L.; KOVACS, K. B.; OLSON, K.; GRAMLICH, L. . Diffusion of an innovative online education intervention: experiences and lessons learned. Public Health, v. 140, n. 780, p. 23-26, 2016.

BAYONA, J. A.; CASTAÑEDA, D. I. Influence of personality and motivation on case method teaching. The International Journal of Management Education, v. 15, n. 3, p. 409-428, 2017.

BLANKLEY, A. I.; KERR, D.; WIGGINS, C. E. The State of Accounting Education in Business Schools: an Examination and Analysis of Active Learning Techniques. In: RUPERT, T. J.; KERN, B. B. (eds.). Advances in Accounting Education: Teaching and Curriculum Innovations. Emerald Publishing Limited. 2017. p. 101-124.

BÖCKER, F. Is Case Teaching More Effective than Lecture Teaching in Business Administration? An Exploratory Analysis. Interfaces, v. 17, n. 5, p. 64-71, 1987.

BOYCE, G.; WILLIAMS, S.; KELLY, A.; YEE, H. Fostering deep and elaborative learning and generic (soft) skill development: The strategic use of case studies in accounting education. Accounting Education, v. 10, n. 1, p. 37-60, 2001.

BROWN, C. E.; FOSTER, D. A. FRA: Teaching Financial Accounting with a Goal-Based Scenario. Intelligent Systems in Accounting, Finance and Management, v. 4, n. 3, p. 173-189, 1995.

BROWN, C. E.; GUPTA, U. G. Applying Case-Based Reasoning to the Accounting Domain. Intelligent Systems In Accounting, Finance And Management, v. 3, p. 205-221, 1994.

BRUNER, R. F. et al. Teaching with Cases to Graduate and Undergraduate Students. Financial Practice and Education, p. 111119,1999

CALIARI, K. V. Z.; ZILBER, M. A.; PEREZ, G. Tecnologias da informação e comunicação como inovação no ensino superior presencial: uma análise das variáveis que influenciam na sua adoção. Rege - Revista de Gestão, v. 24, p. 247-255, 2017.

CHERNEY, I. D. The effects of active learning on students' memories for course content. Active Learning in Higher Education, v. 9, n. 2, p. 152-171, 2008.

CHI, M. T. H. Active-Constructive-Interactive: A Conceptual Framework for Differentiating Learning Activities. Topics in Cognitive Science, v. 1, n. 1, p. 73-105, 2009.

CITTADIN, A.; SANTOS, A. P. dos; GUIMARÃES, M. L. F.; GIASSI, D. O uso de metodologias ativas no ensino da contabilidade de custos. In: CONGRESSO BRASILEIRO DE CUSTOS, 22., 2015, Foz do Iguaçu, RS. Anais... São Leopoldo: Associação Brasileira de Custos, 2015. Disponível em: <periodicos.unesc.net/seminarioECPE/article/download/2128/2017> Acesso em 02/10/2018. 
CULLEN, J.; RICHARDSON, S.; BRIEN, R. O. Accounting Education: An International Exploring the teaching potential of empirically-based case studies. Accounting Education, v. 13, n. 2, p. 251-266, 2004.

FLICK, U. Uma introdução à pesquisa qualitativa. 3. ed. Porto Alegre: Artmed, 2009.

FREIRE, P. Pedagogia do Oprimido. Rio de Janeiro: Paz e Terra, 1987.

GOLICH, V. L. The ABCs of case teaching. International Studies Perspectives, v. 1, n. 1, p. 11-29, 2000.

GRUPE, F. H.; JAY, J. K. Incremental Cases: Real-Life, Real-Time Problem Solving. College Teaching, v. 48, n. 4, p. 123-128, 2000.

GUERRA, C. J. O.; TEIXEIRA, A. J. C. Os Impactos da Adoção de Metodologias Ativas no Desempenho dos Discentes do Curso de Ciências Contábeis de Instituição de Ensino Superior Mineira. Revista de Educação e Pesquisa em Contabilidade (REPeC), v. 10, n. 4, p. 380-397, 2016

HASSALL, T.; LEWIS, S.; BROADBENT, M. Accounting Education : An Teaching and learning using case studies : a teaching note. Accounting Education, v. 7, n. 4, p. 325-443, 1998.

KANE, L. Educators, learners and active learning methodologies. International Journal of Lifelong Education, v. 23, n. 3, p. 275-286, 2004.

KERN, B. B. Enhancing accounting students' problem-solving skills: the use of a hands-on conceptual model in an active learning environment. Accounting Education, v. 11, n. 3, p. 235-256, 2002.

LEAL, E.A.; MEDEIROS, C. R. O.; FERREIRA, L. V. O uso do método do caso de ensino na educação na área de negócios. In: LEAL, E. A.; MIRANDA, G. J.; CASA NOVA, S. (orgs.). P. C. Revolucionando a sala de aula: Como envolver o estudante aplicando técnicas de metodologias ativas de aprendizagem. 1. ed. São Paulo: Atlas, 2017. Cap. 8, p. 93-104.

MARIN, M. J. S.; LIMA, E. F. G.; PAVIOTTI, A. B.; MATSUYAMA, D. T.; SILVA, L. K. D. da; GONZALEZ, C.; DRUZIAN, S.; ILIAS, M. Aspectos das fortalezas e fragilidades no uso das metodologias ativas de aprendizagem. Revista Brasileira de Educação Médica, v. 34 , n. 1 , p. $13-20,2010$

MINNITI, L. F. S.; MELO JÚNIOR, J. S. M.; OLIVEIRA, R. D.; SALLES, J .A. A . The Use of Case Studies as a Teaching Method in Brazil. Procedia - Social and Behavioral Sciences, v. 237, p. 373-377, 2017.

MOILANEN, S. The context-specific conceptions of learning in case-based accounting assignments, students' characteristics and performance. Accounting Education, v. 0, n. 0, p. 1-22, 2017.

MORRISON, T. Actionable Learning A handbook for Capacity Building Through Case Based Learning. Tokio: Asian Development Bank Institute Tokio, 2001.

MOSKOVITZ, M. Beyond the Case Method: It's Time to Teach with Problems. Journal of Legal Education, v. 42, p. 241-270, 1992.

MURIMI, M. W.; KANYI, M.; MUPFUDZE, T.; AMIN, R.; MBOGORI, T.; ALDUBAYAN, K. Factors Influencing Efficacy of Nutrition Education Interventions: A Systematic Review. Journal of Nutrition Education and Behavior, v. 49, n. 2, p. 142-165, 2017.

PINCUS, K. V.; STOUT, D.; SORENSEN, J.; STOCKS, K.; LAWSON, R. Forces for change in higher education and implications for the accounting academy. Journal of Accounting Education, v. 40, p. 1-18, 2017.

POPIL, I. Promotion of critical thinking by using case studies as teaching method. Nurse Education Today, v. 31, n. 2, p. 204207, 2011.

ROGERS, E. M. Diffusion of Innovations. 5. ed. New York: The Free Press, 2003.

RYAN, B.; GROSS, N. Acceptance and diffusion of hybrid corn seed in two Iowa communities. Research Bulletin (Iowa Agriculture and Home Economics Experiment Station), v. 29, n. 372, p. 1, 1950.

SILVEIRA, M. C. B. T. et al. Caminhos da Viação Nordeste LTDA. In: ENCONTRO DA ASSOCIAÇÃO DOS CURSOS DE PÓS GRADUAÇÃO EM ADMINISTRAÇÃO, 41. 2017, São Paulo, SP. Anais... São Paulo: Anpad, 2017.

SOARES, J. B.; SILVA, A. B. da; MACHADO, A. G. C. Os chineses estão chegando! O que fazer com meu marketing mix? O caso da ramadhes \& cia ltda. Revista Raep. Administração: Ensino e Pesquisa. v. 15, n. 1, p. 147-171, 2014.

SOUZA, E. A.; MARION, J. C. Aspectos sobre a utilização do método do caso no ensino da contabilidade: uma abordagem inicial. Contabilidade Vista \& Revista, v. 12 , n. 2, p. 9-31, 2001.

WEIL, S.; OYELERE, P.; RAINSBURY, E. The usefulness of case studies in developing core competencies in a professional accounting programme: a New Zealand study. Accounting Education, v. 13, n. 2, p. 139-169, 2004.

ZHANG, T.; LIU, M.; CHEN, Y. To Deepen the Reform of Teaching Methods in Professional Education. Creative Education, v. 5, p. 1658-1661, 2014. 